\title{
Hacia el envejecimiento activo y saludable: una experiencia de cine-debate en jubilados
}

\section{Towards active and healthy aging: a cinema-debate experience in retirees}

\author{
María de los Ángeles Aguilera-Velasco ${ }^{1}$ (D) 0000-0001-9912-705X \\ Martín Acosta-Fernández ${ }^{1}$ (D) 0000-0003-2075-2325 \\ Blanca Elizabeth Pozos-Radillo ${ }^{1}$ (1) 0000-0002-2284-9043 \\ Sergio Adalberto Franco-Chávez ${ }^{1}$ (D) 0000-0002-9353-6474 \\ ${ }^{1}$ Universidad de Guadalajara $৯$ aaguileracd@ hotmail.com \\ (C) Universidad De La Salle Bajío (México)
}

Palabras clave: jubilación; retiro laboral; intervención; adaptación; transición; cine; cine-debate; filmografía; envejecimiento activo; envejecimiento saludable; determinantes del envejecimiento activo Keywords: retirement; job retirement; intervention; adaptation; transition; cinema; cinema-debate; filmography; active aging; healthy aging; determinants of active aging

Recepción: 16 - 06 - 2021 / Aceptación: 18 - 08-2021

\section{Resumen}

Introducción: ante el potencial del cine para formar hacia el envejecimiento activo y saludable, sumado a las amplias recomendaciones fílmicas existentes, donde los protagonistas son precisamente adultos mayores en proceso de jubilación y vejez, se trazaron los objetivos de analizar la experiencia del cine-debate sobre el envejecimiento saludable y el envejecimiento activo, así como sus determinantes en personas jubiladas de una misma institución educativa. Se buscó también determinar las aportaciones de cada filme durante el proceso de visualización.

Método: se realizó un estudio con enfoque cualitativo y diseño preexperimental descriptivo transversal exploratorio, a través de una intervención socioeducativa de cine-debate, durante un periodo de siete meses previos a la pandemia por COVID-19. Participaron 19 personas. Para la recolección de los datos se utilizó la técnica de grupo focal grabado en audio. Los datos obtenidos se analizaron bajo el fundamento de la fenomenología. Las sesiones de cine-debate se realizaron en la casa de día para jubilados. El programa de intervención se conformó con 25 películas. Todas las películas, excepto Amor en línea, El postre de la alegría, Cuando los hijos regresan y Coco, atendieron la recomendación fílmica del libro Mirar y reflexionar la jubilación, que propone filmes especialmente para personas jubiladas. 
Resultados: dentro del envejecimiento saludable, los participantes analizaron el fomento y el mantenimiento de su capacidad funcional y su interacción consigo mismos, con su pareja, con sus hijos, con la sociedad y con sus entornos. Sobre el envejecimiento activo, lograron visualizar sus oportunidades de salud, de participación y seguridad. Expresaron su sabiduría de vida para enfrentar su jubilación y para vivir con amor. Debatieron sobre sus lazos familiares y comunitarios, así como el empoderamiento, la independencia, la autonomía, la dignidad y el autodesarrollo. También identificaron los determinantes físicos, sociales, económicos, personales (psicológicos y biológicos) y del estilo de vida que influyen en el envejecimiento activo. Se hallaron también las aportaciones particulares de todas las películas para cada parte del proceso educativo.

Conclusión: todos los filmes del ciclo de cine-debate fueron indispensables para lograr la experiencia compartida sobre el envejecimiento saludable y el envejecimiento activo, así como sus determinantes. Se propone hacer nuevas investigaciones con películas de reciente producción y con protagonistas adultos mayores, tal como en este estudio.

\begin{abstract}
Introduction: given the potential of cinema to train towards active and healthy aging, added to the extensive existing film recommendations where the protagonists are precisely older adults in the process of retirement and old age, the objectives of analyzing the experience of cinema-debate on healthy aging and active aging and its determinants, in retired from the same educational institution, as well as determining the contributions of each film during the viewing process.

Method: a study with a qualitative approach and an exploratory cross-sectional descriptive preexperimental design was carried out, through a socio-educational film-debate intervention, during a period of seven months prior to the COVID-19 pandemic. 19 people participated. For data collection, the audio-recorded focus group technique was used. The data obtained were analyzed on the basis of phenomenology. The film-debate sessions were held at the retired day home. The intervention program consisted of 25 films. All the films, except Un profil pour deux, Paulette, Cuando los hijos regresan and Coco, heeded the film recommendation of the book Mirar $y$ reflexionar la jubilación, which proposes films especially for retired people.
\end{abstract}

Results: within healthy aging, the participants analyzed the promotion and maintenance of their functional capacity and their interaction with themselves, with their partner, with their children, with society and with their environments. On active aging, they were able to visualize their 
opportunities for health, participation and safety. They expressed their wisdom of life, to face their retirement and to live with love. They debated their family and community ties, as well as empowerment, independence, autonomy, dignity, and self-development. Also, they identified the physical, social, economic, personal (psychological and biological) and lifestyle determinants that influence active aging. The particular contributions of all the films were also found for each part of the educational process.

Conclusion: all the films in the cinema-debate cycle were essential to achieve the shared experience on healthy aging and active aging and their determinants. It is proposed to do new research with recently produced films and with older adult protagonists, as in this study.

\section{Introducción}

La Organización Mundial de la Salud (OMS) recomienda atender el envejecimiento saludable y activo de la población. Entiende al envejecimiento saludable como el proceso de fomentar y mantener la capacidad funcional, para permitir el bienestar en la vejez, aun cuando se padezcan algunas enfermedades. Para ello, considera importante la interacción permanente entre las personas y los entornos que habitan. Al envejecimiento activo lo concibe la OMS como el proceso de optimización de las oportunidades de salud, participación y seguridad, con el fin de mejorar la calidad de vida de las personas a medida que envejecen. El objetivo del envejecimiento activo es asegurar y empoderar a las personas mayores para que sigan contribuyendo a sus familias, comunidades y economías (OMS, 2015).

Por otra parte, para Cambero y Baigorri (2019), el envejecimiento activo es un concepto biopsicosocial, no limitado a la salud libre de discapacidad, y reconoce, como derechos humanos de las personas mayores, su independencia, participación, dignidad, atención y autodesarrollo. Desde esta perspectiva, sus determinantes son económicos, sociales, físicos, personales (psicológicos y biológicos), comportamentales (estilos de vida) y de acceso a los servicios sociales y de salud. En virtud de lo anterior, la Organización Panamericana de la Salud (OPS) considera urgente desarrollar acciones de salud pública para responder a los desafíos en la búsqueda del envejecimiento activo y saludable en toda la región (OPS, 2021).

En consecuencia, la formación educativa de las personas para la vejez activa y saludable es necesaria. Sin embargo, existen pocas evidencias de intervenciones de preparación educativa para 
la vejez activa y saludable en la región. Destaca una iniciativa en Cuba (Neyra-Corales, NápolesNeyra, Nápoles-Hechavarría, 2017), un par de tesis de licenciatura en Perú (Rosales, 2018; Molocho, 2019), una propuesta brasileña de adaptación de aplicaciones digitales para apoyar el envejecimiento activo en una comunidad de bajos ingresos (Castro et al., 2020), y un estudio brasileño que propone la evaluación de la propia calidad de vida como una estrategia grupal para la promoción de la salud de los adultos mayores (Santos, Oliveira, Barbosa, Nunes y Brasil, 2015).

Lamentablemente, la mayoría de las publicaciones sobre estudios de intervención para el envejecimiento activo y saludable se centran en la promoción de la actividad física, por los beneficios en el incremento de los niveles de autoestima, felicidad, autocuidado, integración del esquema corporal y relaciones intergeneracionales (Martínez, Santaella y Rodríguez-García, 2021). En cambio, otras publicaciones se enfocan en la percepción de las familias sobre el envejecimiento activo y su relación con actividades artísticas (Guerrero y Ros, 2018). Al respecto, sobresale recientemente un estudio tailandés similar, sobre el punto de vista de los adultos mayores acerca del envejecimiento activo y sus perspectivas sobre la salud, la participación y la seguridad (Wongsala, Anbäcken y Rosendahl, 2021).

El análisis de filmes específicos, enfocados en la jubilación y el envejecimiento activo y saludable, puede facilitar la labor de formación educativa de los adultos mayores. Incluso, puede disminuir el sentimiento de soledad. Un estudio reporta la asociación a través del tiempo, entre la frecuencia de participación en las artes receptivas, incluido el cine, con menores probabilidades de soledad en los adultos mayores (Tymoszuk, Perkins, Fancourt y Williamon, 2020). Para Meneghel y de Souza (2021), el cine amplía la comprensión del proceso social del envejecimiento, si se usa en escenarios de educación permanente, involucrando a investigadores, estudiantes y trabajadores de la salud.

De acuerdo con Genovard y Casulleras (2005), se sabe que el cine tiene la capacidad de presentarnos mundos temporales, elicitar reflexiones, evocar recuerdos, activar la nostalgia y modificar la configuración de la experiencia diaria, pues al tener experiencias virtuales se puede disfrutar el mundo desde una nueva luz y ver las cosas de una manera distinta. Esa virtualidad real abre ventanas a mundos agradables, o intolerables, por los cuales se puede circular de forma temporal sin correr el riesgo de moverse, por ello es una ficción con efectos psicológicos muy reales. A juicio de Rodríguez (2011) se considera que, entre los adultos mayores, el conjunto de películas vistas, constituye una cultura cinematográfica que les permite disfrutar los relatos, 
revivirlos, recordarlos, o en algunos casos, llenar vacíos culturales a los que no tuvieron acceso por diversas circunstancias.

El cine-debate, en el caso de la preparación para el envejecimiento activo y saludable en adultos mayores, podría ofrecer un lugar de encuentro, reflexión y diálogo alrededor de filmes. Algunos estudios de preparación para la jubilación a través de cine-debate, en personas jubiladas, han logrado la promoción de habilidades sociales, autoconocimiento, crecimiento personal, compensación de estados emocionales negativos, enriquecimiento de la cultura del envejecimiento, solidaridad entre edades, clases y razas, potenciamiento del desarrollo a partir de los proyectos de vida y uso de redes de apoyo social (Ponce, Cruz y Rodríguez, 2018; Ponce et al., 2017).

En otros casos, el cine-debate ha sido una herramienta útil para la terapia de reminiscencia en personas mayores con demencia, pues detonó recuerdos y funcionó como integrador de diversos elementos de la cultura material simbólica, incluso provocó que las personas obtuvieran recuerdos autobiográficos y cambios positivos en su estado de ánimo y conducta (Maya y Castro, 2017). Por su parte, Igartua, Acosta y Frutos (2009) han encontrado que la identificación y empatía con los personajes, es la principal variable explicativa del disfrute o del malestar afectivo provocado por los dramas. Incluso, Genovard y Casulleras (2005) creen que los espectadores somos conscientes del proceso de envejecimiento de los actores. Explican que esto ocurre porque las estrellas de cine están muy integradas en nuestra vida cotidiana al circular por la televisión, la prensa amarilla o internet. Este conocimiento extracinematográfico se añade a la experiencia del filme y condiciona su recepción.

Existen amplias recomendaciones sobre filmes producidos desde el siglo XX, relacionados con la jubilación y el envejecimiento. Tal vez, en idioma español, la cuenta llegue a más de 300 filmes, más lo que se acumulan cada año. Acorde con Roca (2015), se asume que el sector gerontológico se ha vuelto atractivo para los inversores y ejecutivos de la industria del cine, ya que los actores y directores también han envejecido.

Entre las recomendaciones fílmicas de algunos investigadores, sobresalen las películas: $E l$ Regalo de Cristian Galaz y Andrea Ugalde de 2008, que plantea la amistad como un verdadero tesoro en el devenir del tiempo (Rodríguez, 2012) y estimula actitudes positivas hacia la sexualidad (Árraga y Montiel, 2013); El exótico Hotel Marigold de John Madden en 2011, donde los personajes realizan actividad física, deportiva y sexual (Núñez, 2013) y emigran a India, a partir de su jubilación (Bell, 2017; Martínez, 2017). Están todos bien de Kirk Jones en 2009, como 
ejemplo de relaciones familiares entre un padre que envejece y sus hijos adultos; y la película $E l$ estudiante de Roberto Girault en 2009, que ofrece el panorama de la participación activa y la oportunidad educativa a cualquier edad (Pinazo, 2013); La fiesta de despedida de Tal Granit y Sharon Maymon en 2014, como ejemplo del envejecimiento activo (Ogando-Díaz, 2016). Y el filme Justino, un asesino de la tercera edad, de Santiago Aguilar y Luis Guridi, en 1994 (Guarinos, 2019), donde se aprecia que, aunque el personaje de Justino es central en la película, es difícil identificarse con él.

Cabe destacar, que, tanto en el siglo XX como en el XXI, la representación de la soledad en la vejez en el cine es mínima, aunque sea un problema social de gran importancia fuera de las pantallas. Donio-Bellegarde, Pinazo-Hernandis y Nuñez (2014) encontraron que los filmes que tratan la soledad no representan ni el $0.01 \%$ del catálogo de IMBD. Estos autores, en doce películas, donde se incluye la película Una canción para Marion de Paul Andrew Williams en 2012, observaron a la soledad vinculada con falta de apoyo social, relaciones interpersonales y familiares, bajos ingresos, vivir solo, depresión e ideas suicidas, así como viudez.

Ante el potencial del cine para formar hacia el envejecimiento activo y saludable, sumado a las amplias recomendaciones fílmicas existentes donde los protagonistas son precisamente adultos mayores en proceso de jubilación y vejez, en este estudio se trazaron los objetivos de analizar la experiencia de cine-debate sobre envejecimiento saludable y el envejecimiento activo y sus determinantes, en personas jubiladas de una misma institución educativa y determinar las aportaciones de cada filme durante el proceso de visualización.

Específicamente el estudio se enfocó en analizar las vivencias de fomento y mantenimiento de la capacidad funcional y de la interacción entre las personas y sus entornos, como elementos principales del envejecimiento saludable. Para el envejecimiento activo, el estudio se enfocó en la visualización de las oportunidades de salud, de participación y seguridad, así como las muestras de la sabiduría, lazos familiares y comunitarios, empoderamiento, independencia, autonomía, dignidad y autodesarrollo en los participantes, aunados a la identificación de los determinantes físicos, sociales, económicos, psicológicos, biológicos y de estilo de vida.

\section{Método}

Se realizó un estudio con enfoque cualitativo con diseño preexperimental descriptivo transversal exploratorio en un grupo de jubilados, a través de una intervención socioeducativa de cine-debate, 
Aguilera-Velasco, M. de los Á. et al.

en la ciudad de Guadalajara México, durante un periodo de siete meses previos a la pandemia por COVID-19.

Participaron 19 personas jubiladas que respondieron a una invitación abierta que se realizó en una de sus juntas mensuales en el sindicato donde laboraban. En dicha junta se les explicó el objetivo del proyecto y se les presentó el programa de intervención de cine-debate. Los participantes tenían un promedio de 10 años de jubilados. Habían trabajado en promedio de 26 años, todos en la universidad pública del Estado, con contratos administrativos o de servicio. Su promedio de edad fue 65 años y el $80 \%$ fueron mujeres. Acudían regularmente a la casa de día para jubilados a recibir clases de canto, pintura, teatro, o baile.

Para la recolección de los datos se utilizó la técnica de grupo focal grabado en audio. Se realizó después de la proyección de cada película. Sirvió para recopilar información sobre las experiencias personales de los participantes en torno a las temáticas de las películas, vinculadas con el envejecimiento saludable y con el envejecimiento activo y sus determinantes.

Los datos obtenidos se analizaron bajo el fundamento de la fenomenología y su método fenomenológico interpretativo (Duque y Aristizábal, 2019). Se eligió la fenomenología porque permite captar la vivencia global de una experiencia común (Duque y Aristizabal, 2019; Lyotard, 1989; Mendieta-Izquierdo, Ramírez-Rodríguez y Fuerte, 2015). En el caso de esta investigación, la fenomenología ayudó a descubrir y describir la experiencia de preparación para el envejecimiento activo y saludable a través del cine-debate.

El análisis fenomenológico de los datos se basó en dos premisas: 1) Para captar el fluir y contenido de la conciencia, debemos limitarnos a describir lo que se presenta en ella, sin dejarnos condicionar por las teorizaciones que pudimos haber hecho sobre ese contenido. 2) La descripción señalada antes muestra que en el fluir de la conciencia se presentan, además de referencia a objetos concretos, referencia a esencias ideales (Briones, 2002).

Los audios de los grupos focales se transcribieron en archivos de Word y se analizaron en el software Atlas.ti versión 7, allí se creó una unidad hermenéutica y se seleccionaron las citas que reflejaron vivencias de envejecimiento activo o saludable. Después, cada cita se etiquetó con un código. Los códigos se clasificaron en familias de códigos. A partir de las familias de códigos, se obtuvieron tres categorías de la experiencia vivida, las cuales se esquematizaron en tablas. Una tabla sobre el envejecimiento saludable, otra sobre el envejecimiento activo y la tercera sobre los 
determinantes del envejecimiento activo. A partir de las tablas se describió la experiencia global de los participantes en el cine-debate.

Las sesiones de cine-debate se llevaron a cabo en la casa de día para jubilados de la institución educativa donde había laborado antes de jubilarse. Se gestionó el acceso con el encargado de la casa, quien habilitó el espacio de la sala-comedor para las sesiones semanales de cine-debate. Al fondo del espacio se colocaba una pantalla portátil y se proyectaban las películas. Los investigadores llevaron el equipo necesario. Los participantes se sentaban frente a la pantalla, en sillones y sillas, acomodados en filas, y degustaban palomitas. En 19 ocasiones las funciones de cine comenzaron a las tres de la tarde. En 1 ocasión se llevó la sesión de cine-debate en una sala de cine, a las once de la mañana. En otras cinco ocasiones se llevó a cabo a las doce horas, en la semana cultural de la casa para jubilados.

Antes de la proyección de cada película, se proporcionaron a los participantes los datos generales del filme. Al final de la proyección, se pedía a los participantes que acomodaran las sillas en círculo y se debatía en torno a la película visualizada.

El programa de intervención para el ciclo de cine-debate se conformó con 25 películas. Todas las películas, excepto Amor en línea, El postre de la alegría, Cuando los hijos regresan y Coco, atendieron la recomendación fílmica de un libro especialmente escrito para personas jubiladas (Aguilera, Soltero, Acosta, Franco y Pozos, 2017). Al principio se proyectaron solamente películas dobladas al español, como una solicitud de los participantes, porque no estaban acostumbrados a leer subtítulos. A partir de la novena película, aceptaron el reto de habilitarse en escuchar otro idioma y leer subtítulos. Ello facilitó la proyección de películas en cualquier otro idioma siempre y cuando estuvieran subtituladas.

En la tabla 1 se encuentras las películas 25 películas del ciclo de cine en el mismo orden en que fueron proyectadas. Las películas número 17 a 21 se proyectaron en una misma semana como parte del evento cultural mexicano en Conmemoración del Aniversario de la Revolución Mexicana y el Día de Muertos. 
Tabla 1. Ciclo de cine-debate para la preparación del envejecimiento saludable y el envejecimiento activo, así como sus determinantes en jubilados.

Table 1. Cinema-debate cycle for the preparation of healthy aging and active aging, as well as their determinants in retirees.

\begin{tabular}{|c|c|c|c|c|c|c|}
\hline No. & Título & Título original & Director & País & Año & $\begin{array}{l}\text { Temáticas } \\
\text { principales }\end{array}$ \\
\hline 1 & El regalo & El regalo & $\begin{array}{l}\text { Cristian Galaz y } \\
\text { Andrea Ugalde }\end{array}$ & Chile & 2008 & $\begin{array}{c}\text { Amistad. } \\
\text { Sexualidad. }\end{array}$ \\
\hline 2 & $\begin{array}{l}\text { Un hombre } \\
\text { gruñón }\end{array}$ & $\begin{array}{l}\text { En man som heter } \\
\text { Ove }\end{array}$ & Hannes Holm & Suecia & 2015 & $\begin{array}{l}\text { Ideación suicida. } \\
\text { Jubilación forzada. }\end{array}$ \\
\hline 3 & El camino & The Way & Emilio Estévez & $\begin{array}{l}\text { España y } \\
\text { Estados } \\
\text { Unidos }\end{array}$ & 2010 & $\begin{array}{c}\text { Relaciones con } \\
\text { hijos. } \\
\text { Resistencia a } \\
\text { jubilarse. } \\
\end{array}$ \\
\hline 4 & Almacenados & Almacenados & $\begin{array}{l}\text { Jack Zagha } \\
\text { Kababie }\end{array}$ & México & 2015 & $\begin{array}{c}\text { Brecha } \\
\text { generacional. } \\
\text { Prejubilación. }\end{array}$ \\
\hline 5 & $\begin{array}{l}\text { Están todos } \\
\quad \text { bien }\end{array}$ & Everybody's Fine & Kirk Jones & $\begin{array}{l}\text { Estados } \\
\text { Unidos }\end{array}$ & 2009 & $\begin{array}{l}\text { Desencanto en la } \\
\text { jubilación. } \\
\text { Relaciones con los } \\
\text { hijos. }\end{array}$ \\
\hline 6 & Cleopatra & Cleopatra & $\begin{array}{l}\text { Eduardo } \\
\text { Mignogna }\end{array}$ & Argentina & 2003 & $\begin{array}{l}\text { Desencanto en la } \\
\text { jubilación. } \\
\text { Reorientación de } \\
\text { vida. }\end{array}$ \\
\hline 7 & $\begin{array}{l}\text { El exótico } \\
\text { Hotel } \\
\text { Marigold }\end{array}$ & $\begin{array}{l}\text { The Best Exotic } \\
\text { Marigold Hotel }\end{array}$ & John Madden & $\begin{array}{l}\text { Reino } \\
\text { Unido }\end{array}$ & 2011 & $\begin{array}{l}\text { Migración. } \\
\text { Jubilación. }\end{array}$ \\
\hline 8 & $\begin{array}{c}\text { Justino, un } \\
\text { asesino de la } \\
\text { tercera edad }\end{array}$ & $\begin{array}{l}\text { Justino, un asesino } \\
\text { de la tercera edad }\end{array}$ & $\begin{array}{l}\text { Santiago Aguilar } \\
\text { y Luis Guridi }\end{array}$ & España & 1994 & $\begin{array}{l}\text { Desencanto en la } \\
\text { jubilación. } \\
\text { Amistad. }\end{array}$ \\
\hline 9 & $\begin{array}{l}\text { El amor es } \\
\text { extraño }\end{array}$ & Love Is Strange & Ira Sachs & $\begin{array}{l}\text { Estados } \\
\text { Unidos }\end{array}$ & 2014 & $\begin{array}{l}\text { Desencanto en la } \\
\text { jubilación. } \\
\text { Homofobia. }\end{array}$ \\
\hline 10 & $\begin{array}{l}\text { La fiesta de } \\
\text { despedida }\end{array}$ & Mita-Tova & $\begin{array}{c}\text { Tal Granit y } \\
\text { Sharon Maymon } \\
\end{array}$ & $\begin{array}{c}\text { Israel y } \\
\text { Alemania } \\
\end{array}$ & 2014 & $\begin{array}{c}\text { Amistad. } \\
\text { Eutanasia. }\end{array}$ \\
\hline 11 & $\begin{array}{l}\text { En el último } \\
\quad \text { trago }\end{array}$ & En el último trago & $\begin{array}{l}\text { Jack Zagha } \\
\text { Kababie }\end{array}$ & México & 2014 & $\begin{array}{c}\text { Amistad. } \\
\text { Resignificación de } \\
\text { la vida. }\end{array}$ \\
\hline 12 & $\begin{array}{l}\text { El exótico } \\
\text { Hotel } \\
\text { Marigold 2 }\end{array}$ & $\begin{array}{c}\text { The Second Best } \\
\text { Exotic Marigold } \\
\text { Hotel }\end{array}$ & John Madden & $\begin{array}{l}\text { Reino } \\
\text { Unido }\end{array}$ & 2015 & $\begin{array}{l}\text { Amistad. } \\
\text { Rutina en la } \\
\text { jubilación. }\end{array}$ \\
\hline 13 & $\begin{array}{l}\text { Una canción } \\
\text { para Marion }\end{array}$ & Song for Marion & $\begin{array}{l}\text { Paul Andrew } \\
\text { Williams }\end{array}$ & $\begin{array}{l}\text { Reino } \\
\text { Unido }\end{array}$ & 2012 & $\begin{array}{l}\text { Desencanto en la } \\
\text { jubilación. } \\
\text { Relación con los } \\
\text { hijos. } \\
\end{array}$ \\
\hline 14 & $\begin{array}{l}\text { Un padre no } \\
\text { tan padre }\end{array}$ & $\begin{array}{c}\text { Un padre no tan } \\
\text { padre }\end{array}$ & Raúl Martínez & México & 2016 & $\begin{array}{c}\text { Asilos. } \\
\text { Comunas. }\end{array}$ \\
\hline 15 & Amor en línea & Un profil pour deux & Stéphane Robelin & Francia & 2017 & $\begin{array}{c}\text { Amistad. } \\
\text { Enamoramiento. }\end{array}$ \\
\hline 16 & $\begin{array}{c}\text { El postre de la } \\
\text { alegría }\end{array}$ & Paulette & Jerome Enricó & Francia & 2012 & $\begin{array}{c}\text { Pobreza. } \\
\text { Venta de drogas. }\end{array}$ \\
\hline 17 & Martha & Martha & $\begin{array}{l}\text { Marcelino Islas } \\
\text { Hernández }\end{array}$ & México & 2010 & $\begin{array}{c}\text { Desprotección } \\
\text { social. } \\
\text { Soledad. } \\
\end{array}$ \\
\hline
\end{tabular}




\begin{tabular}{|c|c|c|c|c|c|c|}
\hline No. & Título & Título original & Director & País & Año & $\begin{array}{l}\text { Temáticas } \\
\text { principales }\end{array}$ \\
\hline 18 & $\begin{array}{c}\text { Cuando los } \\
\text { hijos regresan }\end{array}$ & $\begin{array}{l}\text { Cuando los hijos } \\
\text { regresan }\end{array}$ & Hugo Lara & México & 2017 & $\begin{array}{l}\text { Luna de miel en la } \\
\text { jubilación. } \\
\text { Relaciones con los } \\
\text { hijos. }\end{array}$ \\
\hline 19 & $\begin{array}{l}\text { Acapulco, la } \\
\quad \text { vida va }\end{array}$ & $\begin{array}{c}\text { Acapulco, la vida } \\
\text { va }\end{array}$ & $\begin{array}{c}\text { Alfonso Serrano } \\
\text { Maturino }\end{array}$ & México & 2013 & $\begin{array}{c}\text { Amistad. } \\
\text { Resignificación de } \\
\text { la vida. }\end{array}$ \\
\hline 20 & El estudiante & El estudiante & Roberto Girault & México & 2009 & $\begin{array}{c}\text { Amistad. } \\
\text { Reorientación de la } \\
\text { vida. }\end{array}$ \\
\hline 21 & Сoco & Coco & $\begin{array}{l}\text { Lee Unkrich y } \\
\text { Adrián Molina }\end{array}$ & $\begin{array}{l}\text { Estados } \\
\text { Unidos }\end{array}$ & 2017 & $\begin{array}{c}\text { Familia. } \\
\text { Vejez. }\end{array}$ \\
\hline 22 & $\begin{array}{l}\text { Pasante de } \\
\quad \text { moda }\end{array}$ & The Intern & Nancy Meyers & $\begin{array}{l}\text { Estados } \\
\text { Unidos }\end{array}$ & 2015 & $\begin{array}{c}\text { Jubilación. } \\
\text { Reorientación de la } \\
\text { vida. }\end{array}$ \\
\hline 23 & $\begin{array}{l}\text { La estudiante } \\
\text { y el Sr. Henri }\end{array}$ & $\begin{array}{l}\text { L'étudiante et } \\
\text { Monsieur Henri }\end{array}$ & Ivan Calbérac & Francia & 2015 & $\begin{array}{l}\text { Amistad. } \\
\text { Desencanto en la } \\
\text { jubilación. }\end{array}$ \\
\hline 24 & $\begin{array}{c}\text { El encanto del } \\
\text { erizo }\end{array}$ & Le Hérisson & Mona Achache & $\begin{array}{l}\text { Francia e } \\
\text { Italia }\end{array}$ & 2009 & $\begin{array}{c}\text { Amistad. } \\
\text { Enamoramiento. }\end{array}$ \\
\hline 25 & Vivir sin parar & Sein letztes Rennen & Kilian Riedhof & Alemania & 2013 & $\begin{array}{c}\text { Asilos. } \\
\text { Resignificación de } \\
\text { la vida. }\end{array}$ \\
\hline
\end{tabular}

Fuente: directa.

Source: direct.

En el estudio se respetaron las consideraciones éticas de la Declaración de Helsinki publicada por la Comisión Médica Mundial, la Ley General de Salud en materia de Investigación para la Salud en México y los lineamientos de la Comisión Nacional de Bioética. El proyecto está registrado en la Coordinación de Investigación de la Institución donde los investigadores laboran.

\section{$\underline{\text { Resultados }}$}

\section{Experiencias para el envejecimiento saludable}

Respecto del envejecimiento saludable, en los participantes se hallaron reflexiones y debates sobre la capacidad funcional y sobre la interacción entre las personas y los entornos. En torno de la capacidad funcional, el cine-debate contribuyó para su fomento y mantenimiento, pues los participantes la concibieron como capacidad física (tener sexo, trabajar, estar ocupados, ser independiente, viajar, ejercitarse), capacidad mental (decidir sobre la propia vida, planear vivir muchos años) y capacidad emocional (amar, disfrutar la jubilación, persistir en los propios gustos, resolver problemas cotidianos). Las siete películas que contribuyeron para estas experiencias 
Aguilera-Velasco, M. de los Á. et al.

fueron: Acapulco, la vida va; Cleopatra; El exótico Hotel Marigold; La fiesta de despedida; Martha; Pasante de moda y Vivir sin parar. Ver tabla 2.

Tabla 2. Capacidad funcional en jubilados.

Table 2. Functional capacity in retirees.

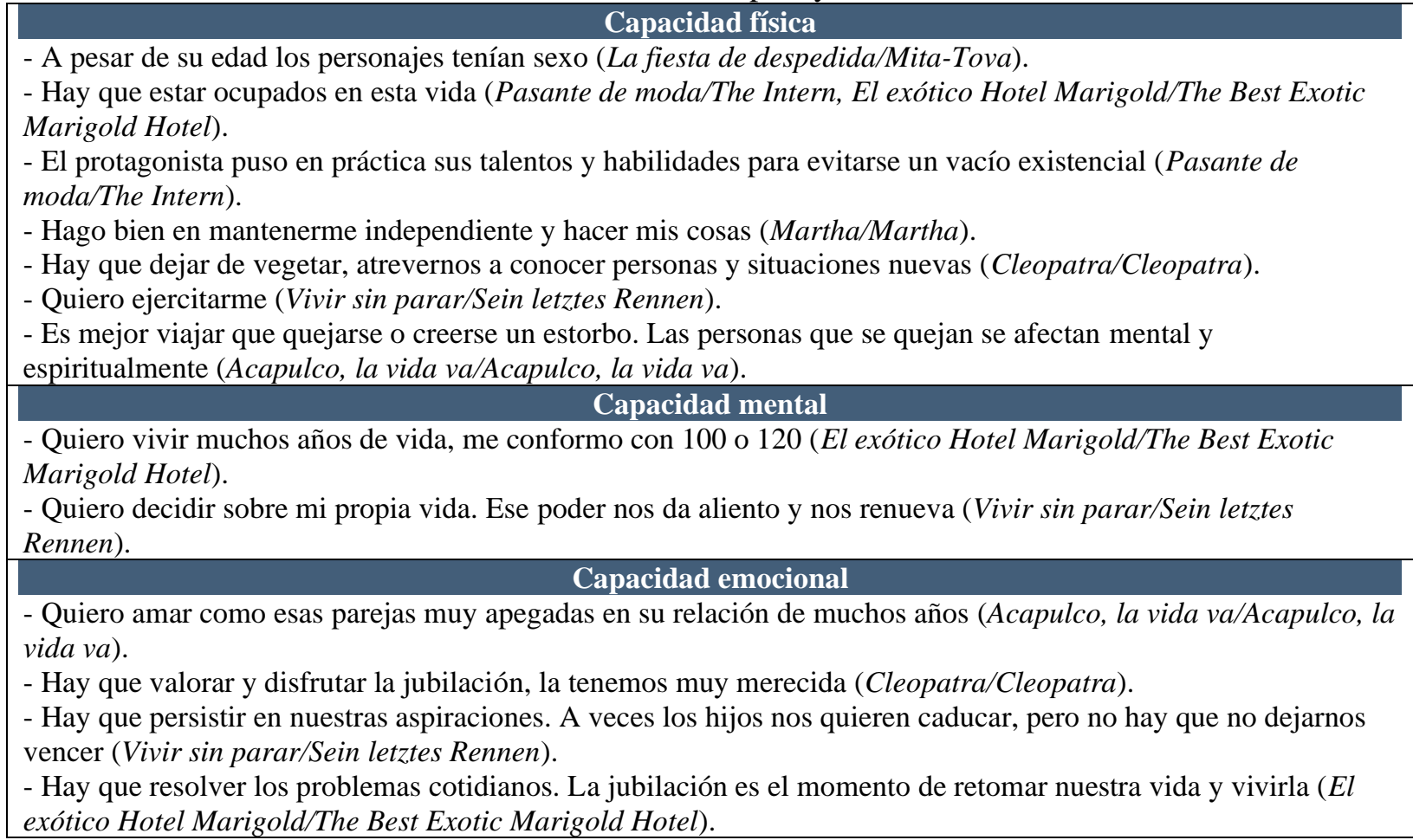

Fuente: directa.

Source: direct.

Acerca de la interacción entre las personas y los entornos de vida, las personas identificaron aspectos que la facilitaban o la obstaculizaban. Entre los aspectos facilitadores mencionaron tener una buena relación consigo mismos (aceptarse, mantener la autoridad, vivir sin egoísmo), con la pareja (sentir atracción, complementarse, amarse), con los hijos (perdonar, demostrarles amor) y con la sociedad en general (aceptar las diferencias, dejar de juzgar, convivir con vecinos, convivir con las personas, ser útiles). Sobre la mejor forma para relacionarse con su entorno comentaron que estaba supeditada a ver la realidad y aceptarla, adaptarse a nuevos entornos y no aceptar reglas absurdas. Las 15 películas que contribuyeron para estas experiencias fueron: Acapulco, la vida va; Almacenados; Amor en línea; Cuando los hijos regresan; El amor es extraño; El encanto del erizo; El estudiante; El exótico Hotel Marigold; El exótico Hotel Marigold 2; Están todos bien; La estudiante y el Sr. Henry; Pasante de moda; Un hombre gruñón; Un padre no tan padre; Una canción para Marion. Véase la tabla 3. 
Tabla 3. Aspectos facilitadores de la interacción entre personas y entornos en jubilados.

Table 3. Aspects facilitators of the interaction between people and environments in retirees.

\section{Facilitadores para la relación consigo mismo}

- Sentía nostalgia por mi aspecto, pero los personajes de la pantalla me han dejado la tarea de reconquistarme a mí misma (Amor en línea/Un profil pour deux).

- Mantengamos la autoridad en la propia casa (Cuando los hijos regresan/Cuando los hijos regresan).

- Vivamos sin egoísmo (El estudiante/El estudiante).

Facilitadores para la relación con la pareja

- Los personajes no perdieron el gusto de sentir atracción por alguien (Acapulco, la vida va/Acapulco, la vida va, El exótico Hotel Marigold 2/The Second Best Exotic Marigold Hotel).

- La pareja de esposos se amaba muy bonito, tenían un gran y hermoso amor (Acapulco, la vida va/Acapulco, la vida va).

- Marion y su esposo eran la contraparte del otro, se motivaban y amaban (Una canción para Marion/Song for Marion).

\section{Facilitadores para la relación con los hijos}

- Me gustó que recapacitaron, reconocieron sus errores y se perdonaron (Un padre no tan padre/Un padre no tan padre).

- A los hijos hay que demostrarles amor. Henry decía "Tápate, no vayas a tener frío" (La estudiante y el Sr. Henry/ L'étudiante et Monsieur Henri).

\section{Facilitadores para la relación con la sociedad}

- Aceptar a cada quien como es, mientras no sean mala leche (Un padre no tan padre/Un padre no tan padre).

- Dejar de juzgar a las personas con otras preferencias sexuales (El amor es extraño/Love Is Strange).

- Convivir con vecinos (Un hombre gruñón/En man som heter Ove).

- Aprender de los jóvenes, orientarlos y ayudarlos: la experiencia conjugada es una buena mezcla (El estudiante/El estudiante).

- Darnos tiempo de conocer a las personas y encontrar su tesoro (El encanto del erizo/Le Hérisson).

- Ser útiles a la sociedad: ayudo pues me necesitan (Pasante de moda/The Intern).

\section{Facilitadores para la relación con el entorno}

- Buscar la realidad y aceptarla, sin cerrar los ojos (Están todos bien/Everybody's Fine).

- Aprendí lo importante de adaptarse a cualquier círculo (Un padre no tan padre/ Un padre no tan padre).

- Al mudarnos la adaptación llega poco a poco (El exótico Hotel Marigold/ The Best Exotic Marigold Hotel).

- Me recordó que yo no acepté reglas absurdas en el trabajo (Almacenados/Almacenados).

Fuente: directa.

Source: direct.

Como obstáculos para tener una buena relación entre las personas y los entornos, los participantes identificaron problemas consigo mismos (permitimos cosas por miedo, somos egoístas, carecemos de equilibrio), problemas con su pareja (viudez), problemas con los hijos (no sabemos demostrarles amor, ni ponerles límites, nos falta comunicarnos, nos sentimos culpables, los apartamos, existen hijos que abusan, despojan, invaden y no dejan ser) y problemas sociales (rechazamos la eutanasia, adultos delincuentes que dañan a los demás). En el entorno identificaron tres problemas: la falta de seguridad social, la soledad que lleva a morir solos y la dificultad para vivir fuera la propia casa. Las 14 películas que contribuyeron para estas experiencias fueron: Acapulco, la vida va; Amor en línea; Cuando los hijos regresan; El amor es extraño; El encanto del erizo; El postre de la alegría; En el último trago; Justino, un asesino de la tercera edad; La estudiante y el Sr. Henry; La fiesta de despedida; Martha; Pasante de moda; Una canción para Mario; Vivir sin parar. Ver tabla 4. 
Tabla 4. Obstáculos para la interacción entre personas y entornos en jubilados.

Table 4. Obstacles for the interaction between people and environments in retirees.

\section{Obstáculos para la relación consigo mismo}

- Permitimos a veces cosas por miedo. Nos sentimos indefensos y pagamos el precio por tener seguridad (En el último trago/En el último trago).

- Carecemos de equilibrio, por cualquier problema nos desviamos (Pasante de moda/The Intern).

- Somos egoístas: me impactó que Mariano no pensó en el dolor que dejaría al morirse, él se dio gusto sin pensar en ella (Acapulco, la vida va/Acapulco, la vida va).

\section{Obstáculos para la relación con la pareja}

- Estoy igual que el marido de Marion, no me acuesto en la cama para no recordarlo (Una canción para Marion/Song for Marion).

- Pierre superó la viudez hasta que él lo decidió. Resurgió cuando se interesó en alguien más (Amor en línea/Un profil pour deux).

- No sabemos decir con palabras lo que sentimos. Arthur quería a su hijo, pero no sabía demostrárselo (Una canción para Marion/Song for Marion).

- A Justino le quisieron manipular su vida (Justino, un asesino de la tercera edad/Justino, un asesino de la tercera edad).

- A esa familia le faltaba comunicación (Cuando los hijos regresan/Cuando los hijos regresan).

- Me cuesta trabajo ponerle límites a mi hija adulta. Piensa que estoy para su servicio (Cuando los hijos regresan/Cuando los hijos regresan).

- Me siento culpable por no darle todo lo que quiere mi hijo adulto (Cuando los hijos regresan/Cuando los hijos regresan).

- Los hijos despojan a sus padres del único patrimonio que tienen y los dejan a la deriva. Abusan de la buena fe de sus padres (Cuando los hijos regresan/Cuando los hijos regresan).

- Existen hijos abusivos. Muchas compañeras no vienen al cine porque tienen el compromiso de cuidar a sus nietos (Pasante de moda/The Intern).

- Nosotros apartamos a nuestros hijos, a veces no nos dejamos querer, los controlamos y provocamos su rechazo (La estudiante y el Sr. Henry/L'étudiante et Monsieur Henri).

- Regresaron sus hijos casados e invadieron su casa. Él no les puede decir que se vayan (En el último trago/En el último trago).

- A veces los hijos no nos dejan ser: en la película los adultos mayores del asilo están enojados porque no los dejan ser (Vivir sin parar/Sein letztes Rennen).

$$
\text { Obstáculos para la relación con la sociedad }
$$

- Yo no tomaría la decisión de quitarme la vida, por mi creencia religiosa: Dios me da la vida y él me la quita. Confío en que él haga lo mejor para mí (La fiesta de despedida/Mita Tova).

- He sabido de señoras ya grandes que en su casa reciben jovencitos para venderles droga (El postre de la alegría/ Paulette).

-Hay personas que no tienen más opción que dañar a los demás: a Justino nadie le dio apoyo, a nadie le interesaron sus sentimientos (Justino, un asesino de la tercera edad/Justino, un asesino de la tercera edad).

\section{Obstáculos para la relación con el entorno}

- Muchas personas realmente viven en esa condición de inseguridad social, sin futuro (Martha/Martha).

-Algunos jubilados mueren solos en nuestra propia universidad (Martha/Martha).

-Fue una vida muy triste para el Erizo no tener seguridad social, vivió una eterna amargura (El encanto del erizo/ Le Hérisson).

-Ha de ser difícil vivir en una casa ajena, porque estás acostumbrado a lo que te gusta, entonces te desilusionas ( $E l$ amor es extraño/Loves Is Strange).

\section{Fuente: directa.}

Source: direct.

\section{Experiencias para el envejecimiento activo}

Respecto del envejecimiento activo, en los participantes se fomentaron debates sobre sus oportunidades de salud, de participación y seguridad, así como experiencias de sabiduría, lazos 
familiares y lazos comunitarios. También deliberaron sobre su empoderamiento, independencia, autonomía, dignidad y autodesarrollo.

En las oportunidades de salud de halló el deseo de ejercitarse. En las oportunidades de participación en encontró el deseo de tener pareja, pasear, trascender, ser solidarios, viajar y ser felices. Dentro de las oportunidades de seguridad hallaron pertinente irse a asilos de personas conocidas, no dejarse despojar de la propia casa y pedir ayuda al DIF. Cabe aclarar que en México el DIF son las siglas para el Sistema para el Desarrollo Integral de la Familia. Además, en la visualización de sus oportunidades de salud, de participación y de seguridad, hallaron una forma positiva y activa para compensar sus pérdidas (falta de pareja, soledad). Las 8 películas que contribuyeron para la visualización de las oportunidades de envejecimiento activo fueron: Cleopatra; El amor es extraño; El regalo; En el último trago; La fiesta de despedida; Martha; Un hombre gruñón y Vivir sin parar. Ver tabla 5.

Tabla 5. Oportunidades de salud, de participación y seguridad en jubilados.

Table 5. Health, participation and safety opportunities for retirees.

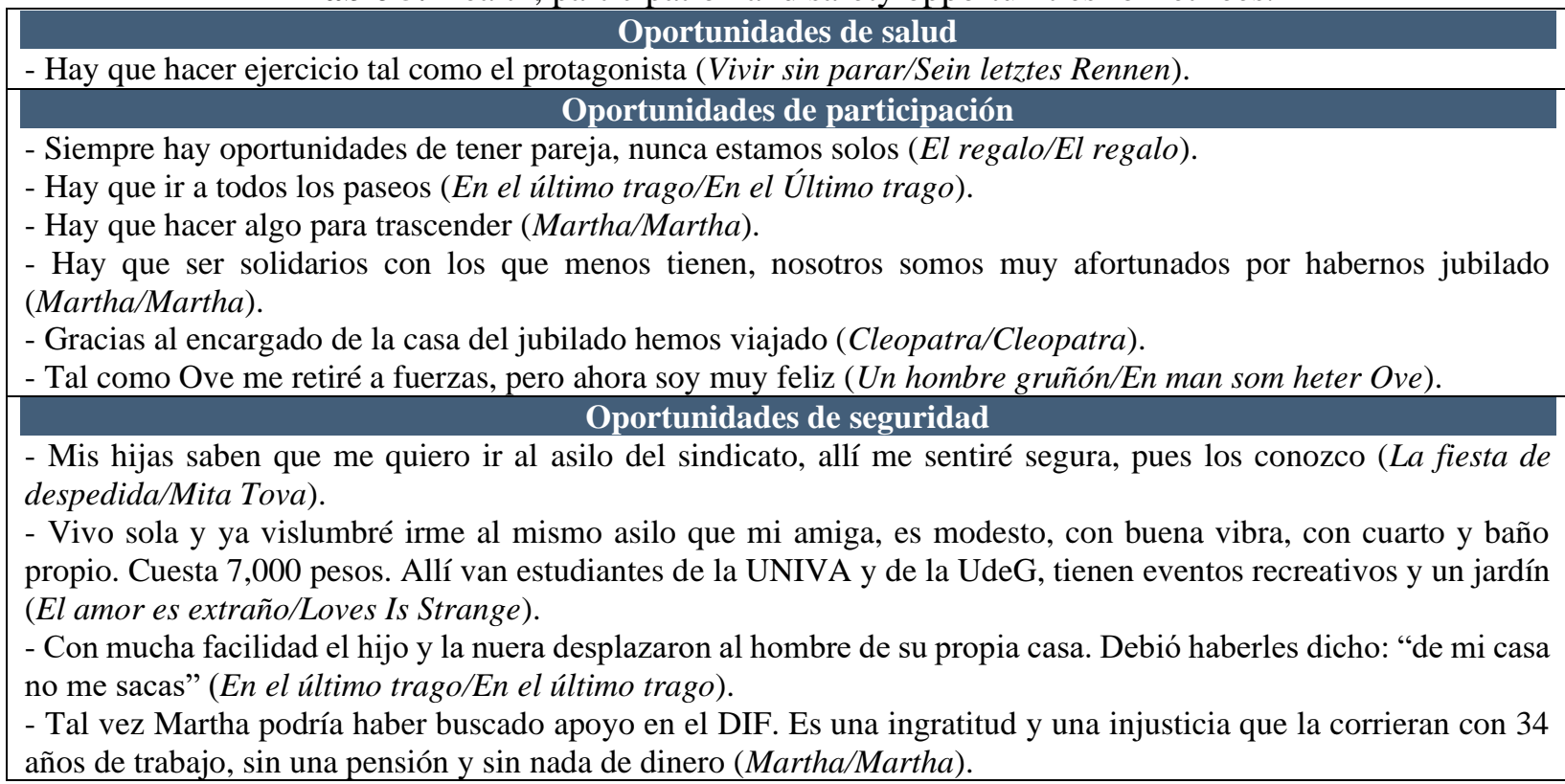

Fuente: directa.

Source: direct.

Dentro de las reflexiones de sabiduría se halló sabiduría sobre la vida, sobre la jubilación y sobre el amor. En la sabiduría sobre la vida las personas consideraron importante disfrutarla, vivirla en el presente, con sus alegrías y tristezas, encontrarle sentido y hacer lo que les gusta. Contribuyeron 
en estas reflexiones siete películas: Cleopatra; El camino; El exótico Hotel Marigold 2; El postre de la alegría; La estudiante y el Sr. Henry; Un padre no tan padre y Vivir sin parar.

En la sabiduría sobre la jubilación las personas concluyeron en que les dio miedo y alegría, pero les ayudó compartir la experiencia, no sentirse indispensables, estudiar, valorarse, no perder la ilusión en el amor y aprender de los jóvenes. Para este tipo de sabiduría del retiro laboral aportaron seis películas: Almacenados; Amor en línea; Cuando los hijos regresan; El estudiante; Pasante de moda y Un hombre gruñón. Sobre la sabiduría en el amor valoraron la importancia de perdonar y perdonarse, no ser egoísta, convivir con cariño, valorar a la pareja e hijos, no juzgar por la apariencia, vivir en la verdad y buscar la estabilidad emocional. Al respecto, fueron seis filmes los que facilitaron estas reflexiones: Acapulco, la vida va; Coco; El amor es extraño; El encanto del erizo; El estudiante y Están todos bien. La película El estudiante contribuyó tanto para el debate de la sabiduría en la jubilación como de la sabiduría en el amor. Ver la tabla 6.

Tabla 6. Sabiduría en jubilados.

Table 6. Wisdom in retirees. Sabiduría sobre la vida

- Disfrutar cada momento de nuestra vida, porque la vida es bella y para la felicidad no hay edad (El regalo).

- La vida no se elige, se vive (El camino/The Way).

- El mejor regalo que tenemos es el presente. Estamos en una etapa en que el tiempo es oro (El exótico Hotel Marigold 2/The Second Best Exotic Marigold Hotel).

- La vida tiene alegrías y tristezas. Los seres humanos cambiamos, nos adaptamos, disfrutamos y sufrimos ( $U n$ padre no tan padre/Un padre no tan padre).

- Encontrar un sentido de vida para tener una ilusión por la cual vivir (El postre de la alegría/Paulette).

- Hay que hacer lo que nos gusta, vivir las oportunidades, aprovecharlas (La estudiante y el Sr. Henry/L'étudiante et Monsieur Henri).

- La vida es echar a perder, aprender, dejarnos querer, aceptar las cosas, aceptar la vida (La estudiante y el Sr. Henry/L'étudiante et Monsieur Henri).

- Mientras estemos vivos, todo puede pasar, por eso siempre hay que luchar por lo que uno quiere (Cleopatra/Cleopatra).

- La vida es un maratón, con días de altibajos y pendientes, pero hay que continuar (Vivir sin parar/Sein letztes Rennen).

Sabiduría sobre la jubilación

- Cuando me jubilé tenía alegría y miedo. La película nos invita a disfrutar el presente y a las personas de este momento (Un hombre gruñón/En man som heter Ove).

- Si uno tiene la experiencia tiene que transmitirla (Almacenados/Almacenados).

- Nadie somos indispensables en el trabajo (Almacenados/Almacenados).

- Nunca es tarde para estudiar, siempre tenemos algo que aprender (El estudiante/El estudiante).

- En la jubilación podemos valorar lo que realmente somos (Cuando los hijos regresan/Cuando los hijos regresan).

- No hay que perder la ilusión del amor, recibir las cosas inesperadas sin miedo, como un regalo de la vida (Amor en línea/Un profil pour deux).

- El protagonista tenía experiencia y sabiduría y quitó las barreras que su jefa joven le ponía (Pasante de moda/The Intern).

- Siempre podemos aprender de todos los que nos rodean, sean más jóvenes o más viejos (Pasante de moda/The Intern). 
- Es necesario saber perdonar y perdonarnos (Coco/Coco).

- Ante una enfermedad mortal, no hay que ser egoístas, hay que pensar en la familia hasta el final (Acapulco, la vida va/Acapulco, la vida va).

- Puede haber convivencia y cariño entre adultos mayores y jóvenes (El estudiante/El estudiante).

- El valor de la familia, el apoyo de la esposa y de los hijos, son importantes en cualquier momento (El estudiante/El estudiante).

- Hay que buscar al ser humano que está detrás de una apariencia (El encanto del erizo/Le Hérisson).

- Es doloroso, pero es importante vivir en la verdad (Están todos bien/Everybody's Fine).

- Todo se resuelve con estabilidad emocional (El amor es extraño/Loves Is Strange).

\section{Fuente: directa.}

Source: direct.

Se hallaron también reflexiones sobre los lazos familiares y comunitarios. En los lazos familiares los participantes debatieron en torno de la viudez, la pareja, la familia, los hijos, las madres y los nietos. Contribuyeron en estas reflexiones 12 películas: Acapulco, la vida va; Amor en línea; Cleopatra; Coco; Cuando los hijos regresan; El regalo; Están todos bien; La fiesta de despedida; Martha; Un hombre gruñón; Un padre no tan padre y Una canción para Marion.

En el debate de los lazos comunitarios se resaltó el apoyo entre mujeres, el valor de la amistad y de los vecinos. Hubo aportaciones de 11 películas: Acapulco, la vida va; Coco; El amor es extraño; El encanto del erizo; El estudiante; En el último trago; Justino, un asesino de la tercera edad; Martha; Un hombre gruñón; Una canción para Marion y Vivir sin parar. Hubo 5 películas que contribuyeron tanto para el debate sobre lazos familiares como comunitarios: Acapulco, la vida va; Coco; Martha; Un hombre gruñón y Una canción para Marion. Véase la tabla 7.

Tabla 7. Lazos familiares y lazos comunitarios en jubilados.

Table 7. Family ties and community ties in retirees.

Lazos familiares
- Ante la viudez hay que seguir viviendo, divirtiéndonos y recordar (Una canción para Marion/Song for Marion).
- Hay que decirles que los queremos, no dejar pasar el tiempo porque pueden morir (Una canción para
Marion/Song for Marion).
- Mi esposo y yo nos casamos siendo jubilados, a lo mejor, pueden encontrar el amor de su vida por aquí (El
regalo/El regalo).
- Cuando te casas tienes que respetar tus creencias (Amor en línea/Un profil pour deux).
- Las parejas siguen teniendo su encanto físico y en su trato hacia el otro (Acapulco, la vida va/Acapulco, la vida
va).
- No hay nada más valioso que la familia, no debemos de perder nuestras tradiciones (Coco/Coco).
- Hay que ser tolerante y aceparlos como son, aunque nos cueste trabajo. También es importante reconocernos en
- un espejo (Un padre no tan padre/Un padre no tan padre).
- Hay que poner a nuestros hijos en manos de Dios (Un padre no tan padre/Un padre no tan padre).
- Mi madre es muy optimista, no tiene dinero, pero tiene muchas personas que la quieren (Martha/Martha).
- Estoy aprendiendo en ver en mi hija y mi nieta a mi espejo (Cuando los hijos regresan/Cuando los hijos regresan).
- La familia es un punto central muy importante, para identificar quién soy y para qué sirvo (Un hombre gruñón/En
- man som heter Ove).
- Nunca es tarde para recuperar el tiempo perdido con los hijos (Están todos bien/Everybody's Fine).
- Ella tenía mucho amor de madre para dar, por eso buscaba a quien querer (Cleopatra/Cleopatra).


Lazos comunitarios

- Nos tenemos que apoyar mucho entre las mujeres para que no haya violencia (Vivir sin parar/Sein letztes Rennen).

- En la última etapa de la vida, los amigos hacen la fuerza. La amistad es difícil que se rompa (En el último trago/En el último trago).

- Salgo mucho con ustedes ahora, para no sentirme sola (Una canción para Marion/Song for Marion).

- Todo el pasado con amigos de alguna forma nos impacta (Acapulco, la vida va/Acapulco, la vida va).

- Nosotros somos un grupo bien bonito, nos respetamos, nos escuchamos (Acapulco, la vida va/Acapulco, la vida $v a)$.

- La amistad ayuda a sobrellevar mejor la jubilación (Acapulco, la vida va/Acapulco, la vida va).

- Ante las pérdidas se necesita de redes personales para poder salir adelante (Un hombre gruñón/En man som heter Ove).

- Hay muchos jubilados que se encierran en su casa y no salen para ningún lado (Justino, un asesino de la tercera edad/Justino, un asesino de la tercera edad).

- Es importante tener un apoyo social. Con las amistades te sientes apoyada y no te sientes sola (El amor es extraño/Loves Is Strange).

- Respeto a toda la gente para que me respeten también (El estudiante/El estudiante).

- Con preguntarle a los vecinos cómo están, impactamos un poquito en su vida (Martha/Martha).

- Un vecino es saber qué cuentas con alguien enfrente que te puede apoyar y escuchar, con quien puedes acudir (Coco/Coco).

- La niña y el japonés le dieron amor, cariño y la aceptaron como era (El encanto del erizo/Le Hérisson).

\section{Fuente: directa.}

Source: direct.

En cuanto a los valores del envejecimiento activo tales como empoderamiento, independencia, autonomía, dignidad y autodesarrollo, los participantes encontraron varias acciones para llevar a cabo. Por ejemplo, para el empoderamiento consideraron importante hablar sobre sus necesidades y tomar conciencia, disfrutar su casa, enseñar a los hijos la responsabilidad de ser adultos, no ser niñeras de sus nietos, denunciar en caso necesario, no ceder ante los gustos, atreverse, decidir y luchar por lo que se quiere. Las películas que facilitaron estas reflexiones fueron seis: Almacenados; Cleopatra; Cuando los hijos regresan; En el último trago; El exótico Hotel Marigold y Vivir sin parar.

Respecto a la independencia, las personas concluyeron en seguir sus gustos, dejar ir a los hijos y ponerles límites, probar la libertad, no ser permisivos, ni dejarse manipular, ejercer la voluntad anticipada, gozar la independencia económica y la pensión digna. Para estas disertaciones participaron siete filmes: Cleopatra; Cuando los hijos regresan; En el último trago; Justino, un asesino de la tercera edad; La fiesta de despedida; Pasante de moda y Un padre no tan padre.

Sobre la autonomía se debatió en torno a la eutanasia, la diferencia entre géneros, las enfermedades incapacitantes, los mandatos sociales sobre el deber ser y sobre la capacidad de decisión sobre la propia vida. Fueron 3 películas las que aportaron para dichas reflexiones: Cleopatra; Justino, un asesino de la tercera edad y La fiesta de despedida. 
Hacia el envejecimiento activo y saludable: una experiencia de cine-debate en jubilados

En cuanto a la dignidad, se encontraron debates en torno al maltrato de los adultos mayores, los límites entre los hijos, la conservación del espacio de vida, el derecho a negarse a ser abusados. Facilitaron estos razonamientos cuatro filmes: Cleopatra; Cuando los hijos regresan; En el último trago y Pasante de moda.

Sobre el autodesarrollo se debatió sobre las oportunidades de vida tras la viudez, el cambio de actitudes, las ilusiones amorosas, la trascendencia, la madurez, la valentía, el autoengaño, las alternativas de vida, la preparación, la evolución y el ser positivos. Siete filmes aportaron para dichas reflexiones: Almacenados; Amor en línea; Cleopatra; El camino; El exótico Hotel Marigold 2; Un padre no tan padre y Una canción para Marion. La película Cleopatra contribuyó en la reflexión de los cinco valores del envejecimiento activo (tabla 8).

Tabla 8. Empoderamiento, independencia, autonomía, dignidad y autodesarrollo en jubilados.

Table 8. Empowerment, independence, autonomy, dignity and self-development in retirees.

\section{Empoderamiento}

- Hay que hablar acerca de lo que necesitamos y queremos, tomar conciencia (En el último trago/En el último trago).

- Necesitamos nuestro espacio en nuestra casa (Cuando los hijos regresan/Cuando los hijos regresan).

- Hay que enseñar a los hijos a ser responsables y pagar por sus compromisos (Cuando los hijos regresan/Cuando los hijos regresan).

- No ser las niñeras de nuestros nietos, porque ya trabajamos y tuvimos muchas presiones (Cuando los hijos regresan/Cuando los hijos regresan).

- Con la denuncia en la televisión, el protagonista movió la conciencia de las personas (Vivir sin parar/Sein letztes Rennen).

- Nunca cedió el protagonista. El vivir sin parar y hacer lo que nos gusta es muy interesante (Vivir sin parar/Sein letztes Rennen).

- En nuestro trabajo éramos muy responsables y profesionales (Almacenados/Almacenados).

- Hay que atreverse y decidir, para aprovechar cuanta oportunidad se dé. Las mujeres nos atrevemos más que los hombres, tomamos más la decisión de enfrentar todas las circunstancias de diversión que se nos presentan, sobre todo en esta etapa de la jubilación. Los hombres se encierran más en sí mismos (Cleopatra/Cleopatra).

- Luchar por lo que queremos, no dejarnos. Pase lo que pase, conseguirlo (El exótico Hotel Marigold/The Best Exotic Marigold Hotel).

Independencia

- Aunque ya estés grande y te prohíban las cosas, no hay que hacerles caso, hay que cumplir tu gusto (En el último trago/En el último trago).

- Yo no quería que mi hija se fuera a México, pero terminé apoyándola y agradecí a Dios (Un padre no tan padre/Un padre no tan padre).

- Cuando los límites se desbordan hay que usar estrategias para decirles a los hijos "hasta aquí" (Cuando los hijos regresan/Cuando los hijos regresan).

- Hicimos un buen trabajo cuando los hijos son independientes, productivos y felices (Cuando los hijos regresan/ Cuando los hijos regresan).

- Cuando no tienes una vida propia tratas de vivir a través de tus hijos. Necesitamos dejarlos ir, que ellos resuelvan sus problemas y tengan su vida propia (Pasante de moda/The Intern).

- Cleopatra se convirtió en un espíritu libre porque probó la libertad, ya no quiso regresar a su casa (Cleopatra/Cleopatra).

- Cleopatra no tenía razón para vivir con ese mal hombre, nomás de verle la cara yo pensaba: más vale sola que mal acompañada (Cleopatra/Cleopatra).

- No hay que ser permisivos, ni dejarnos manipular por nadie. Los hijos querían imponerse a Justino (Justino, un asesino de la tercera edad/Justino, un asesino de la tercera edad).

- Es importante la voluntad anticipada. Pero no estamos acostumbrados a escribir qué es lo que queremos. Se podrían evitar muchos problemas que a veces consideraciones normales (La fiesta de despedida/Mita Tova).

- Somos una generación afortunada, tenemos independencia económica y logramos una pensión digna (En el último trago/En el último trago).

№ 27, Vol. 13 (3), 2021. ISSN 2007 - 0705, pp.: 1 - 32

-18 - 
- No eran unos asesinos porque los ayudaban a bien morir (La fiesta de despedida/Mita Tova).

- Un hombre no sabe vivir solo, siempre necesita compañía y una mujer. Las mujeres somos más maduras y más fuertes para soportar la muerte (La fiesta de despedida/Mita Tova).

- Hay que tomar medidas por si nos llega una enfermedad incapacitante, sobre todo las que estamos solas o casi solas, para no ser una carga para nuestros familiares. Pensar en una casa de descanso. ¿Qué lugar quiero? ¿Cómo lo quiero? También tomar en cuenta todo lo legal, como la eutanasia, para ir disponiendo todo eso. Es un tema muy fuerte, pero me sirve para ir pensando en tomar medidas al respecto (La fiesta de despedida/Mita Tova).

- Decidir tal como lo hizo Cleopatra: ¿Es porque quiero o porque debo? (Cleopatra/Cleopatra).

- Valorar lo que tenemos, no esperar más. Tenemos una jubilación, ingresos y la capacidad de decisión sobre nuestra vida (Justino, un asesino de la tercera edad/Justino, un asesino de la tercera edad).

$$
\text { Dignidad }
$$

- Nos quieren tratar como si fuéramos niños, sin reconocer que somos adultos. Deben respetar nuestra dignidad de seres humanos adultos. Nosotros mismos podemos poner un alto, diciendo lo que queremos y lo que no queremos, aun cuando nuestra voz ni siquiera sea fuerte o ya no tengamos las fuerzas. Yo preferiría estar en un lugar donde me atendiera otra persona, antes de que mis hijos me maltrataran (En el último trago/En el último trago).

- Mis hijos tienen límites, me tienen que pedir permiso si quieren dejar algo en mi casa, no tienen autorización de llegar y meterse a la hora que quieran (Cuando los hijos regresan/Cuando los hijos regresan).

- Con la edad se siente la pérdida de territorio, perdemos nuestro espacio, hay que conservarlo sin perder a la familia (Cuando los hijos regresan/Cuando los hijos regresan).

- Los hijos deben respetar nuestra casa, porque ya no es la (s)tuya, pueden visitarnos o por una emergencia, pero ya no pueden disponer de ella (Cuando los hijos regresan/Cuando los hijos regresan).

- Tenemos que aprender a decir no, sin sentirnos culpables. Nos es fácil Muchas veces aceptamos ciertas situaciones que no queremos, como cuidar a los nietos, para no sentirnos malos (Pasante de moda/The intern).

- No tenemos que estar con otras personas que no queremos, ni siquiera por el deber (Cleopatra/Cleopatra).

- Muchas personas se amargan porque se casan para evitar estar solas (Cleopatra/Cleopatra). Autodesarrollo

- Enviudar es triste, pero tenemos que superarlo. Cuando murió mi esposo lo extrañé y no quería ni pasar a nuestro cuarto. Después entendí que él nunca me había hecho nada, que me quería muchísimo ¿Por qué voy a huir de alguien que me ama? Y empecé a entrar y a quedarme, a tomarme mi lugar otra vez. Ahora duermo muy feliz y me siento acompañada (Una canción para Marion/Song for Marion).

- Nunca es tarde para cambiar de actitud. A veces hay que cambiar de ambiente o de situación. Puede parecernos que los cambios no son buenos, pero el resultado sí es bueno (Un padre no tan padre/Un padre no tan padre).

- El protagonista revivió por su nueva ilusión amorosa. El amante pueden ser los viajes, la pintura, la cocina, todo (Amor en línea/Un profil pour deux).

- Comenzamos el camino siendo unos y terminamos transformados. Así como el protagonista paró en cada lugar para regar las cenizas de su hijo, así debemos nosotros de parar en ciertos caminos para reflexionar lo que sigue (El camino/The Way).

- Asimilar la jubilación con mucha madurez, pues se tiene por un lado la ilusión de retirarse con salud, y por otro lado es un desprendimiento de toda una vida (Almacenados/Almacenados).

- Cleopatra tuvo valentía para ver dentro de ella. A veces no nos atrevemos a ver dentro de nosotros, para descubrir cosas nuevas (Cleopatra/Cleopatra).

- A veces vivimos en un engaño constante. Cleopatra se dio cuenta de lo que quería hacer y terminó haciendo lo que quería: andar en el mundo y andar de un lugar a otro (Cleopatra/Cleopatra).

- Hay que salir a buscar alternativas, no quedarse en un solo lugar. El marido de Cleopatra no salía a buscar dinero para la luz ni para lo que se acababa (Cleopatra/Cleopatra).

- Hay que prepararse, Cleopatra sí se preparó. Al marido ni de trabajar le daban ganas (Cleopatra/Cleopatra).

- Hay que evolucionar, como Cleopatra. Al principio era sumisa. Luego experimentó sentirse libre, fluyó con todas que le iban llegando y eso le permitió disfrutar el mundo de una manera diferente. Podemos evolucionar tomando decisiones, moviéndonos de las situaciones que no nos gustan, no siendo predecibles, aunque nos duela. Es decir, salir de la zona de confort y decir: yo quiero, yo deseo y yo puedo (Cleopatra/Cleopatra).

- Pensar más en nosotros, ser más positivos y disfrutar (El exótico Hotel Marigold 2/The Second Best Exotic Marigold Hotel).

Fuente: directa.

Source: direct. 


\section{Experiencias sobre los determinantes del envejecimiento activo}

Respecto de los determinantes del envejecimiento activo, en los debates de los participantes se hallaron reflexiones sobre determinantes físicos, sociales, económicos, personales y del estilo de vida.

Se encontraron como determinantes físicos las limitaciones físicas, el deterioro de la edad, enfermedades terminales y el retiro laboral. Para ello participaron cinco filmes: Acapulco, la vida va; El amor es extraño; En el último trago; La fiesta de despedida y Vivir sin parar.

Como determinantes sociales se encontró la falta de aprobación legal de la eutanasia, la falta de valor y la violencia hacia los adultos mayores, las costumbres y creencias tradicionales, la delincuencia entre algunos ancianos, la falta de empatía con otras preferencias sexuales, no saber negarse y el encierro de los hombres al jubilarse. Fueron 9 películas las que contribuyeron con estos hallazgos: Cleopatra; El amor es extraño; El estudiante; El postre de la alegría; En el último trago; La fiesta de despedida; Pasante de moda; Un padre no tan padre y Vivir sin parar.

En los determinantes económicos se halló la necesidad de ahorrar, se reconoció que algunos adultos mayores delinquen o matan por dinero, que existen millones de mexicanos que no tiene derecho a una pensión y trabajan para comer, se sintió la impotencia de no saber cómo ayudarlos

y se reconoció que algunas personas están felices con el apoyo del gobierno mexicano. Para estas reflexiones se apoyaron en la visualización de cuatro filmes: Justino, un asesino de la tercera edad; El postre de la alegría; La fiesta de despedida y Martha.

Dentro de los determinantes personales se hallaron como limitantes de un envejecimiento activo las creencias religiosas acerca de la eutanasia, la dureza de carácter sobre todo en los varones, las desilusiones amorosas, la falta de valores, la soledad que lleva a la depresión o al suicidio, prejuzgar por las apariencias, los traumas y las heridas de la niñez, la falta de conciencia sobre la muerte, el encerrarse en uno mismo para no sufrir, no prepararse, abandonarse, tener actitudes negativas, no tener valores, estar enfermos de odio y amargura, y no realizar deportes. Contribuyeron en estas reflexiones. Para estas reflexiones contribuyeron 16 filmes: La fiesta de despedida; En el último trago; Una canción para Marion; Amor en línea; El postre de la alegría; Martha; Un hombre gruñón; El estudiante; Coco; El encanto del erizo; La estudiante y el sr. Henry; Cleopatra; El exótico hotel Marigold; Justino, un asesino de la tercera edad; El amor es extraño y Vivir sin parar. 
En el estilo de vida, se encontraron determinantes tales como la violencia psicológica, física y económica, las carencias económicas, la viudez, la actitud en el trabajo, el deseo de jubilarse y mantener la independencia. Las cinco películas que facilitaron estas conclusiones fueron: En el último trago; El postre de la alegría; Pasante de moda; Almacenados y Justino, un asesino de la tercera edad.

Tabla 9. Determinantes del envejecimiento activo en jubilados.

Table 9. Determinants of active aging in retirees. Determinantes físicos

- A veces estás luchando contigo misma, con tus propias limitaciones físicas (La fiesta de despedida/Mita Tova).

- Me vi reflejada porque yo también corría en maratones, correr también era mi vida (Vivir sin parar/Sein letztes Rennen).

- Las personas grandes en ocasiones ya no tienen ni siquiera el carácter, ya cualquiera los domina (En el último trago/En el último trago).

- El protagonista tiene un tumor cerebral y lo toma con tranquilidad, con calma (Acapulco, la vida va/ Acapulco, la vida va).

- Tenemos que retirarnos, son etapas de la vida que todos vamos a pasar (El amor es extraño/Loves Is Strange). Determinantes sociales

- Nunca va a ser nuestra realidad, porque la eutanasia no es legal en México (La fiesta de despedida/Mita Tova).

- No se valora a los adultos mayores en nuestra sociedad (En el último trago/En el último trago).

- Las costumbres y las creencias nos hacen vivir de cierto modo (Un padre no tan padre/En el último trago).

- La delincuencia es algo que no sucedería muy normalmente en una persona mayor (El postre de la alegría/Paulette).

- A veces la preferencia sexual es una desorientación (El estudiante/El estudiante).

- No podemos decir que no queremos pasar por malas personas (Pasante de moda/The Intern).

- La violencia se manifiesta de muchas formas (Vivir sin parar/Sein letztes Rennen).

- Los hombres que se jubilan se encierran en su mundo, una mujer hace actividades (Cleopatra/Cleopatra).

- Cuesta un poquito aceptarlo, pero las relaciones homosexuales es lo que está pasando (El amor es extraño/Loves Is Strange).

Determinantes económicos

- Tenemos que ahorrar mucho (La fiesta de despedida/Mita Tova).

- La necesidad obligó a Paulette a delinquir, porque no quería vivir de indigente. Para mí estuvo bien porque la falta de dinero la estaba amargando. Con dinero se sintió relajada y contenta (El postre de la alegría/Paulette).

- Nosotros tenemos una forma digna de vivir, pero hay millones de personas de la tercera edad que no tienen esa dicha, ellos tienen que trabajar para comer (El postre de la alegría/Paulette).

- ¿De qué manera podemos ayudarles a las personas sin seguridad social? Yo no puedo sostener a otra persona, con el salario que tengo no puedo sostener a otra persona (Martha/Martha).

- Las personas están felices con el apoyo del gobierno mexicano, lo esperan con ansiedad, les da sentido de valía, de ser productivos, porque son personas que sobreviven con ayuda de sus hijos (Justino, un asesino de la tercera edad/Justino, un asesino de la tercera edad).

- Justino primero mató para que lo dejaran de fastidiar, luego para tener dinero e irse a Benidorm con su amigo (Justino, un asesino de la tercera edad/Justino, un asesino de la tercera edad).

Determinantes personales

- Antes las personas morían en sus casas y no se les prolongaba la vida (La fiesta de despedida/Mita Tova).

- La eutanasia es un asunto muy personal (La fiesta de despedida/Mita Tova).

- Yo no estoy de acuerdo con la eutanasia, ni con el aborto, por mis creencias religiosas (La fiesta de despedida/Mita Tova).

- Todo en la vida es un aprendizaje, hasta el dolor y la muerte (En el último trago/En el último trago).

- El carácter duro no permite expresar el amor que se tiene por otra persona (Una canción para Marion/Song for Marion).

- Me enamoré de una ilusión y ahora estoy sufriendo (Amor en línea/Un profil pour deux). 
- Los valores nos impiden hacer daño a los jóvenes o delinquir (El postre de la alegría/Paulette).

- La depresión se presenta en personas solas que no tienen dinero para vivir, aunque conozco personas pobres que son positivas y alegres (Martha/Martha).

- Algunos viudos se quieren suicidar porque se quedan solos (Un hombre gruñón/En man som heter Ove).

- Regularmente juzgamos por lo que vemos nada más así por fuera (Un hombre gruñón/En man som heter Ove).

- Necesitamos sanar heridas y traumas de la infancia (Un hombre gruñón/En man som heter Ove).

- Tenemos que aprender a vivir con la muerte, porque es una constante (El estudiante/El estudiante).

- A veces hay que regresar al pasado para poder saber una verdad sobre uno mismo (Coco/Coco).

- Detrás de una actitud, una mala cara, un comportamiento, siempre hay una historia (El encanto del erizo/Le Hérisson).

- A veces los adultos mayores varones se encierran en sí mismos para no sufrir (La estudiante y el Sr. Henry/ L'étudiante et Monsieur Henri).

- La estudiante ocultó sus sentimientos para no ser criticada ni juzgada, le faltaba autoestima (La estudiante y el Sr. Henry/L'étudiante et Monsieur Henri).

- Cleopatra tenía aspiraciones y estaba preparada, nunca se abandonó como el esposo (Cleopatra/Cleopatra).

- La actitud positiva es un factor elemental en la vida (El exótico hotel Marigold/The Best Exotic Marigold Hotel).

- Justino no tenía valores de vida para salir adelante. Los valores te ponen límites (Justino, un asesino de la tercera edad/ Justino, un asesino de la tercera edad).

- Hay personas enfermas de odio y amargura, y se vuelven crueles (Justino, un asesino de la tercera edad/Justino, un asesino de la tercera edad).

- A Justino lo echaron del trabajo y se sintió inservible. Descargó su coraje matando (Justino, un asesino de la tercera edad/ Justino, un asesino de la tercera edad).

- Los paseos, las caminatas y hacer algún deporte ayudan a tener esa alegría interior (El amor es extraño/Loves Is Strange).

- Hay que vivir sin parar (Vivir sin parar/Sein letztes Rennen).

\section{- Vemos violencia psicologica, física y economica de vida}

- Vemos violencia psicológica, física y económica en algunos adultos mayores (En el último trago/En el último trago).

- No estaba acostumbrada a las carencias económicas, al enviudar se reorientó hacia la delincuencia (El postre de la alegría/Paulette).

- Disfrutar el trabajo sin sentirnos indispensables y sin estrés, dándonos tiempo para nosotros (Pasante de moda/The Intern).

- Cuando llegó el tiempo de jubilarme, yo contaba los años, los meses, los días, las horas (Almacenados/Almacenados).

- Es importante mantener nuestra independencia lo más posible (Justino, un asesino de la tercera edad/Justino, un asesino de la tercera edad).

\section{Fuente: directa.}

Source: direct.

\section{Aportaciones del ciclo de cine-debate}

Las personas consideraron que el cine-debate les aporta conocimiento y claridad, les cambia la vida, los ayuda a mantener sus convicciones y a conocer lo que deben evitar, los incita al altruismo, funciona como terapia, a través del cine se ven reflejados y los llena de alegría y esperanza. Véase la tabla 10. 
Tabla 10. Aportaciones del cine-debate en jubilados.

Table 10. Contributions of the cinema-debate in retirees.

\section{Aporta conocimiento y claridad}

- Nos aporta claridad de muchas situaciones. Cada escena en lo particular nos hace reflexionar en que efectivamente necesitamos cambiar nuestra forma de ver o pensar (En la sesión de evaluación/In the evaluation session).

- Me gustó mucho descubrir las etapas de la jubilación, porque entendí lo estoy viviendo y lo que otra persona está viviendo (En la sesión de evaluación/In the evaluation session).

- Conocí otras culturas, con cada película, de cada país (En la sesión de evaluación/In the evaluation session).

\section{Cambia la vida}

- Nos cambió la forma de ver la vida, yo la veo desde otra forma más positiva (En la sesión de evaluación/In the evaluation session).

- Identificamos cosas positivas para ver siempre hacia adelante (En la sesión de evaluación/In the evaluation session).

- Con todas las películas me digo "Esto aplica para mí en mi vida, voy a hacerlo" (En la última sesión del ciclo de cine mexicano/ In the last session of the Mexican film series).

- Me ayudó a ver que no importa la edad para salir adelante, simplemente es cambiar de actitud y hacer lo que quieres (El exótico hotel Marigold/The Best Exotic Marigold Hotel).

Ayuda a mantener las convicciones

- Este análisis y el compartir experiencias me ha ayudado a mantenerme firme en mis convicciones (Cuando los hijos regresan/Cuando los hijos regresan).

\section{Ayuda a conocer lo que debemos evitar}

- Nos ayuda a recordar a los personajes gruñones que alejan a la gente. Me gusta tenerlos presentes, es valiosísimo, porque me acuerdo de esos personajes y tengo claro lo que debo evitar (En la sesión de evaluación/In the evaluation session).

- Casi en todas las películas encontré algo similar a mi vida, algo para corregir y adaptar. Me sirvió para vivir mejor mi jubilación (En la sesión de evaluación/In the evaluation session).

- El ver a protagonistas que toman determinaciones equivocadas, son enseñanzas para la vida real (En la última sesión del ciclo de cine mexicano/ In the last session of the Mexican film series).

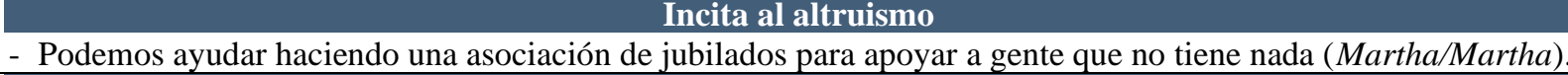

\section{Es una terapia}

- Voy mucho al cine, como una especie de terapia. No lo cambio por nada (En la sesión de evaluación/In the evaluation session).

Nos reflejamos

- El cine sirve para reflejarnos, pero sobre todo nos ayuda también a recordar a los personajes gruñones que alejan a la gente, me gusta tenerlos presentes, es valiosísimo, porque me acuerdo de esos personajes y tengo claro lo que debo evitar (En la sesión de evaluación/In the evaluation session).

- Yo me vi reflejada varias veces. Decía: yo he estado en esa situación, a lo mejor me he portado así. En la película del Erizo dije: "No debo de juzgar por las apariencias, debo darme la oportunidad de conocer a las personas". Es un regalo ver todas las películas, porque podemos conocer lo que a cada uno nos ha pasado, lo que estamos viviendo, lo que sentimos (En la sesión de evaluación/In the evaluation session).

- Me vi reflejada porque no me animo a dejar de cuidar a mis nietos, ni a dejar de atender a mis hijos. No se me da decirles que no puedo (En la sesión de evaluación/In the evaluation session).

\section{Nos llena de alegría y enseñanzas}

- A mí desde niña me ha fascinado el cine, cada película que veo me llena el corazón, me llena de alegría y enseñanzas (Me ha servido En la sesión de evaluación/In the evaluation session).

mucho porque antes entraba en fuertes depresiones y no me levantaba (En la sesión de evaluación/In the evaluation session).

Fuente: directa.

Source: direct. 


\section{Discusión}

El ciclo de cine-debate contribuyó para el fomento y mantenimiento del envejecimiento activo y el envejecimiento saludable en el sentido en que lo recomiendan los organismos internacionales (OMS, 2015; OPS, 2021) y algunos autores (Cambero y Baigorri, 2019).

Los participantes concibieron su envejecimiento saludable como el proceso de fomentar y mantener su capacidad funcional e interactuar consigo mismos, con su pareja, sus hijos, su comunidad y su entorno, tal como menciona la OMS que es lo idealmente esperado. Se encontró cierta la concepción de algunos autores (Meneghel y de Souza, 2021) de que el cine amplía la comprensión del proceso social del envejecimiento, si se usa en escenarios de educación permanente. En ese sentido, fue útil la visualización de la película El exótico Hotel Marigold, propuesta por algunos autores (Bell, 2017; Martínez, 2017; Núñez, 2013) pero también el resto de la filmografía incluida en este estudio.

Respecto del envejecimiento activo, las recomendaciones fílmicas de otros autores también fueron adecuadas, por ejemplo, la película El Regalo (Rodríguez, 2012), La fiesta de despedida (Ogando-Díaz, 2016), El estudiante (Pinazo, 2013) y Están todos bien (Pinazo, 2013). Además, fue valiosa la recomendación de una película sobre la vivencia de la soledad, a través del filme Una canción para Marion (Donio-Bellegarde et al., 2014), aunque en el caso de este estudio, la película aportó muchos más elementos que solamente la experiencia de la soledad, pues resultó eficaz para apreciar la importancia de los lazos familiares y comunitarios, el autodesarrollo y la influencia de los determinantes personales. Este resultado coincide con lo obtenido en otros estudios (Tymoszuk et al., 2020) que reportaron que existen menos probabilidades de soledad en los adultos mayores que participan en artes receptivas, incluido el cine.

Acerca de la recomendación del filme Justino, un asesino de la tercera edad, es cierto, tal como lo describe Guarinos (2019), que los participantes no se identifican con el protagonista por razones obvias, pero los participantes de este estudio mostraron empatía hacia los determinantes económicos, personales y del estilo de vida que provocaron su conducta, y entendieron su deseo de independencia, autonomía y establecimiento de lazos comunitarios.

Se logró crear a través de la experiencia educativa de cine-debate un lugar de encuentro, reflexión y diálogo alrededor de filmes. Se promovió, además del conocimiento sobre el envejecimiento activo y saludable, la promoción de habilidades sociales, el autoconocimiento, el crecimiento personal, la compensación de estados emocionales negativos, el enriquecimiento de la 
cultura del envejecimiento, la solidaridad y el potenciamiento de los proyectos de vida y redes de apoyo social, tal como algunos autores también lo hallaron en sus estudios (Ponce et al., 2017; Ponce et al., 2018).

En esta investigación también fue muy importante la empatía que los participantes sintieron con los protagonistas y con su sentimiento de satisfacción provocado por los dramas, tal como lo hallaron previamente algunos autores (Igartua et al., 2009).

\section{Conclusiones}

Se lograron los objetivos de analizar la experiencia de cine-debate sobre el envejecimiento saludable y el envejecimiento activo y sus determinantes, en personas jubiladas de una misma institución educativa, y determinar las aportaciones de cada filme durante el proceso de visualización.

Con el estudio se confirmó que el cine tiene gran potencial para la formación social de las personas mayores, siempre y cuando se utilice conjuntamente con filmografía cuyos protagonistas vivan el proceso de jubilación y vejez. También se logró confirmar que la formación educativa de las personas para su vejez activa y saludable no solamente es necesaria, sino también posible, y que la visualización de filmes específicos, enfocados en el envejecimiento activo y envejecimiento saludable, facilitan en gran medida la labor de formación educativa de los adultos mayores. Inclusive, ayudan para disminuir su sentimiento de soledad.

Entre los principales resultados, se encontró que, para el envejecimiento saludable, fueron 22 películas las que aportaron para su promoción y mantenimiento. Es decir, todas las películas del ciclo de cine, excepto los filmes El regalo; El camino; Coco.

- Para el tema de la capacidad funcional, tanto física, como mental y emocional, las películas $E l$ exótico hotel Marigold; Cleopatra; Vivir sin parar, fueron las que hicieron mayores aportaciones.

- La identificación de los elementos facilitadores de la interacción consigo mismos pudo apreciarse mejor a través de los filmes El estudiante; Amor en línea; Cuando los hijos regresan, aportaron más. 
- Para la reflexión sobre los elementos facilitadores de la interacción con la pareja, los filmes Acapulco, la vida va; El exótico Hotel Marigold 2; Una canción para Marion, fueron los que más aportaron.

- Para la identificación de los elementos facilitadores de la interacción con los hijos, se recibieron mayores aportaciones por medio de las películas Un padre no tan padre; La estudiante y el $\mathrm{Sr}$. Henry.

- Los elementos facilitadores de la interacción con la sociedad, se lograron visualizar preferentemente a través de las películas Pasante de moda; El amor es extraño; Un hombre gruñón; El encanto del erizo.

- Los elementos facilitadores de la interacción con el entorno, fueron bien ejemplificados con las películas Están todos bien; Almacenados.

- Los obstáculos para la interacción con uno mismo, se visualizaron mejor a través de la película En el último trago.

- Los obstáculos para la interacción con los hijos, se ejemplificaron a través del polémico filme Justino, un asesino de la tercera edad.

- Los elementos que obstaculizan la sana interacción con la sociedad se apreciaron bien a través de los filmes La fiesta de despedida; El postre de la alegría, sobre todo porque abordaron temas tabúes de la sociedad, tales como la eutanasia y la venta de narcóticos.

- En cuanto a los obstáculos para una sana interacción con el entorno, la película Martha fue ideal.

Respecto del envejecimiento activo los 25 filmes del ciclo de cine hicieron aportaciones, sin embargo, algunos de ellos aportaron más en alguna área específica, como se aprecia a continuación.

- Para apreciar las oportunidades en salud, el filme Vivir sin parar aportó profundamente, aunque también contribuyó para otros aspectos del envejecimiento activo, como por ejemplo la sabiduría de vida, los lazos comunitarios y el empoderamiento.

- Para ejemplificar las oportunidades de participación social, fueron cuatro películas las que más aportaron: El regalo; En el último trago; Martha; Un hombre gruñón. Cabe aclarar que estas películas también aportaron en otros aspectos importantes del envejecimiento activo. 
- Las oportunidades de seguridad se apreciaron muy bien en las películas La fiesta de despedida; El amor es extraño.

- La sabiduría sobre la vida se apreció bien a través de los filmes El camino; El exótico hotel Marigold; Un padre no tan padre; El postre de la alegría; La estudiante y el Sr. Henry.

- La sabiduría necesaria para la jubilación se ejemplificó preferentemente a través de las películas Almacenados; El estudiante; Cuando los hijos regresan; Amor en línea; Pasante de moda. Dichas películas mostraron vivencias desde la prejubilación a través de la película Almacenados, la luna de miel de la jubilación (Cuando los hijos regresan) y la reorientación (El estudiante, Amor en línea y Pasante de moda).

- La sabiduría para el amor se apreció bien a través de las películas Coco; Acapulco, la vida va; El encanto del erizo; Están todos bien. Dichas películas también fueron efectivas para apreciar la importancia de los lazos familiares y comunitarios.

- Para ejemplificar la importancia de los lazos familiares fue ideal la película Una canción para Marion. Esta película también promovió idealmente los lazos comunitarios y el autodesarrollo.

- Los lazos comunitarios, o la falta de ellos, se apreciaron a través de la película Justino, un asesino de la tercera edad.

- El empoderamiento se logró visualizar preferentemente a través de las películas Cleopatra y El exótico hotel Marigold. Cabe destacar que el filme Cleopatra también sirvió para apreciar la independencia, la autonomía, la dignidad y el autodesarrollo.

Acerca de los determinantes del envejecimiento activo, se obtuvieron aportaciones de 19 películas. Algunos filmes aportaron para varios determinantes, como se puede apreciar en las tablas superiores.

- Para apreciar el efecto de los determinantes físicos, fueron ideales 4 filmes: Vivir sin parar; La fiesta de despedida; Acapulco, la vida va; En el último trago. Estos filmes muestran a personas dispuestas a vencer sus limitaciones físicas de la edad en aras de alcanzar sus sueños.

- Los determinantes sociales se pudieron apreciar a través de los filmes El amor es extraño; Un padre no tan padre. Ambas películas muestran los efectos nocivos de los prejuicios sociales. La primera película sobre personas con una preferencia sexual diferente y la segunda hacia las personas que viven en comunas. 
- Los determinantes económicos se apreciaron a través de 3 películas donde los protagonistas tuvieron serios problemas financieros para sobrevivir: Justino, un asesino de la tercera edad; Martha; El postre de la alegría.

- Los determinantes personales del envejecimiento activo se ejemplificaron al menos a través de 8 filmes: Cleopatra; El estudiante; Un hombre gruñón; Amor en línea; Coco; El encanto del erizo; Una canción para Marión; El exótico hotel Marigold. En todos los casos, estos filmes mostraron protagonistas decididos y emprendedores.

- Para la apreciación de los determinantes del estilo de vida los filmes Pasante de moda y Almacenados fueron ideales, pues mostraron las dos caras de la moneda.

Se concluye considerando que los 25 filmes del ciclo de cine-debate fueron indispensables para lograr la experiencia compartida sobre el envejecimiento saludable y el envejecimiento activo y sus determinantes. Se propone hacer nuevas investigaciones con películas de reciente producción, cuyos protagonistas sean igualmente adultos mayores.

\section{$\underline{\text { Referencias }}$}

Aguilera, M. A., Soltero, R., Acosta, M., Franco, S. A. y Pozos, B. E. (2017). Mirar y reflexionar la jubilación. Recomendación de películas para fomentar vivencias del ocio. Guadalajara: Página Seis.

Árraga, M. y Montiel, N. (2013). Salud, cine y educación sexual para adultos mayores. Omnia, 19(3), 86-97. http://www.redalyc.org/pdf/737/73730059008.pdf

Bell, C. (2017). The best exotic marigold hotel: International retirement migration on FILM. Journal of Ageing and Society, 37(10), 1975-1986. http://doi.org/10.1017/S0144686X1600057X

Briones, G. (2006). Epistemología de las ciencias sociales. Bogotá: Instituto Colombiano para el Fomento de la Educación Superior, ICFES.

Cambero. S. y Baigorri, A. (2019). Envejecimiento activo y ciudadanía senior. EMPIRIA Revista de Metodología de Ciencias Sociales, 43(2), 59-87. https://doi.org/10.5944/empiria.43.2019.24299 
Castro, P. C., Romano, L. B., Frohlich, D., Lorenzi, L. J., Campos, L. B., Paixão A., et al. (2020) Tailoring digital apps to support active ageing in a low income community. PLoS ONE 15(12): e0242192. https://doi.org/10.1371/journal.pone.0242192

Donio-Bellagarde, M., Pinazo-Hernandis, S. y Nuñez, T. (2014). La representación cinematográfica de la soledad en la vejez: selección de films. INFAD Revista de Psicología, 2(1),

https://www.researchgate.net/profile/Monica_Bellegarde_Nunes/publication/267760370_

LA_REPRESENTACION_CINEMATOGRAFICA_DE_LA_SOLEDAD_EN_LA_VEJE

Z_SELECCION_DE_FILMS/links/54c7aba50cf22d626a36d400/LA-

REPRESENTACION-CINEMATOGRAFICA-DE-LA-SOLEDAD-EN-LA-VEJEZ-

\section{SELECCION-DE-FILMS.pdf}

Duque H. y Aristizábal E. T. (2019). Análisis fenomenológico interpretativo: Una guía metodológica para su uso en la investigación cualitativa en psicología. Pensando Psicología, 15(25), pp. 1-24. https://doi.org/10.16925/2382-3984.2019.01.03

Genovard, C. y Casulleras, D. (2005). La imagen de la vejez en el cine. Iconografía virtual e interpretación psicológica. Boletín de Psicología, 83(marzo), 7-20. https://www.uv.es/seoane/boletin/previos/N83-1.pdf

Guarinos, V. (2018). Envejecimiento (de tópicos) activo (s) en el cine español de las décadas del “bienestar”. Área Abierta. Revista de Comunicación Audiovisual y Publicitaria, 19(1), 5973.

https://www.researchgate.net/profile/Virginia_Guarinos/publication/331824641_Envejeci miento_de_topicos_activos_en_el_cine_espanol_de_las_decadas_del_bienestar/links/5c9 0029ba6fdcc38175cab18/Envejecimiento-de-topicos-activos-en-el-cine-espanol-de-lasdecadas-del-bienestar.pdf

Guerrero, C. y Ros, M. D. (2018). Familias y envejecimiento activo y saludable de personas con discapacidad. En el libro: Conocimientos, investigación y prácticas en el campo de la salud. Volumen IV. Pérez-Fuentes, M. C., Molero, M. M., Gázquez, J. J., Martos, A., Barragán, A., \& Simón, M. M. (Comps). Murcia: ASUNIVEP. http://hdl.handle.net/10201/86974

Igartua, J. J., Acosta, T. y Frutos, F. J. (2009). Recepción e impacto del drama cinematográfico: El papel de la identificación con los personajes y la empatía. Global Media Journal Edición Iberoamericana 6(11), 1-18. http://hdl.handle.net/10366/111087 
Lyotard, J. F. (1989). La fenomenología. Barcelona: Paidós.

Martínez, J. R. (2017). Las personas mayores a través del cine. Gerokomos, 28(2), 56-62. Recuperado de http://scielo.isciii.es/scielo.php?script=sci_arttext\&pid=S1134$\underline{928 X 2017000200056}$

Martínez, N., Santaella, E. y Rodríguez-García, A. M. (2021). Beneficios de la actividad física para la promoción de un envejecimiento activo en personas mayores. Revisión bibliográfica. Retos, 39, 829-834. https://doi.org/10.47197/retos.v0i39.74537

Maya, A. y Castro, M. (2017). Evocación de memorias a través del cine de oro mexicano. Ética y Cine Journal, 7(3), 43-49. https://dialnet.unirioja.es/servlet/articulo?codigo=6775807

Mendieta-Izquierdo, G., Ramírez-Rodríguez, J. C. y Fuerte, J. A. (2015). La fenomenología desde la perspectiva hermenéutica de Heidegger: una propuesta metodológica para la Salud Pública. Revista Facultad Nacional de Salud Pública, 33(3), 435-443. https://www.redalyc.org/articulo.oa?id=120/12041781014

Meneghel, S. N. y de Souza, M. C. (2021). Envelhecimento com dependência: o que mostra o cinema. Ciência \& Saúde Coletiva, 26(1), 67-76. https://doi.org/10.1590/1413$\underline{81232020261.31362020}$

Molocho, C. E. (2019). Impacto del programa Autocuidado para una vejez activa sobre la funcionalidad del adulto mayor. Centro de Salud Monsefú. Tesis de Licenciatura en Enfermería. Universidad Señor de Sipán, Pimentel-Perú. https://hdl.handle.net/20.500.12802/6492

Neyra-Corales, A., Nápoles-Neyra, N. y Nápoles-Hechavarría, P. I. (2017). Proyecto sociocultural Más vida: alternativa para una vejez activa. REDEL. Revista Granmense de Desarrollo Local, 1(2), 1-15. https://revistas.udg.co.cu/index.php/redel/article/view/446

Nuñez, T. (2013). Cine y envejecimiento activo: la imagen de la actividad física en las películas. $\begin{array}{lllll}\text { Escritos } & \text { de } & \text { Psicología } & \text { (Internet), } & 6(2),\end{array}$ https://dx.doi.org/10.5231/psy.writ.2013.2006

Ogando-Díaz, B. (2016). Geriatría y cine: una mirada desde la salud. Revista de Medicina y Cine, $12(4)$, 196-204. https://revistas.usal.es/index.php/medicina_y_cine/article/download/15505/16103 
Organización Mundial de la Salud. (2015). Informe Mundial sobre el envejecimiento y la salud. OMS: WHO/FWC/ALC/15.0. https://www.who.int/ageing/publications/world-report2015/es/

Organización Panamericana de la Salud. (2021). Plan de acción sobre la salud de las personas mayores incluido el envejecimiento activo y saludable. CD49/8. https://www.paho.org/hq/index.php?option=com_content\&view=article\&id=13634:health y-aging\&Itemid=42449\&lang=es

Pinazo, S. (2013). Reflexionando sobre la vejez a través del cine. Una aproximación incompleta. Información Psicológica, 105(junio), 91-109. cv.org/db/docu/130712133750I74jH508v36E.pdf

Ponce, T. M., Cruz, C. A. y Rodríguez, B. (2018). Jubilación y calidad de vida. Impacto de la implementación de un programa educativo de preparación para la jubilación. Convención Internacional de Salud, Cuba Salud 2018, 1-8. https://convencionsalud2018.sld.cu/index.php/connvencionsalud/2018/paper/viewPDFInt erstitial/1289/1090

Ponce, T. M., Matheu, D., Díaz, O., Cruz, C. A., Cabrera, G. M. y Fernández, N. (2017). Impacto de la implementación de un programa educativo de preparación de los trabajadores para la jubilación. Revista Cubana de Salud y Trabajo, 18(2), 21-25. https://www.medigraphic.com/pdfs/revcubsaltra/cst-2017/cst172d.pdf

Roca, E. (2015). De Cameron a Haneke, un punti inicial para analizar el cine gerontológico. Revista de Medicina y Cine, 11(2), 105-108. https://revistas.usal.es/index.php/medicina_y_cine/article/download/13149/13515

Rodríguez, R. (2011). El impacto emocional del cine en las personas adultas mayores y la búsqueda del sentido de la vida. IV Congreso Iberoamericano de Universidades para Mayores CIUUMM 2011 Aprendizaje a lo largo de la vida, envejecimiento activo y cooperación internacional en los programas universitarios para mayores, 761-767. https://www.rua.ua.es/dspace/bitstream/10045/20143/1/761.pdf

Rodríguez, R. (2012). Siete tramas de amor y la metáfora de la estrella. Análisis de la película chilena El Regalo. Revista Comunicación, 21(1), 52-59. https://revistas.tec.ac.cr/index.php/comunicacion/article/download/814/728 
Rosales, L. E. (2018). Programa educativo: envejecimiento saludable, y conocimiento del adulto mayor. Centro de Salud Víctor Larco. Tesis de Licenciatura en Enfermería. Universidad Nacional de Trujillo, Perú.

Santos, L. F., Oliveira, L. M. A. C., Barbosa, M. A., Nunes, D. P. y Brasil, V. V. (2015). Calidad de vida de los mayores que participan en el grupo de promoción de la salud. Enfermería Global, 14(40), 1-11. https://scielo.isciii.es/scielo.php?script=sci_arttext\&pid=S1695$\underline{61412015000400001}$

Tymoszuk, U., Perkins, R., Fancourt, D. y Williamon, A. (2020). Cross-sectional and longitudinal associations between receptive arts engagement and loneliness among older adults. Social Psychiatry Psychiatric Epidemiology 55, 891-900. $\underline{\text { https://doi- }}$ org.wdg.biblio.udg.mx:8443/10.1007/s00127-019-01764-0

Wongsala, M., Anbäcken, E. y Rosendahl, S. (2021). Active ageing - perspectives on health, participation, and security among older adults in northeastern Thailand - a qualitative study. $\begin{array}{llll}B M C & \text { Geriatrics } & \text { 21(41), }\end{array}$ https://bmcgeriatr.biomedcentral.com/articles/10.1186/s12877-020-01981-2 